\title{
Prediction of the Site of Coronary Artery Lesion in Acute Inferior Myocardial Infarction with Right Sided Precordial Lead (V4r)
}

\author{
MS Alam, M Ullah, SU Ulabbi, MM Haque, R Uddin, MS Mamun, AAS Majumder \\ National Institute of Cardiovascular Diseases, Dhaka, Bangladesh.
}

Keywords:

Coronary artery

disease,

Myocardial

infarction, Lead

$V_{4} r$.

\begin{abstract}
:
Background: The patient with inferior wall AMI, site of culprit lesions is an important determinant of outcome. Patient with RV infarction have a poor prognosis whereas those with occlusion of LCX have a good prognosis. Early diagnosis and treatment substantially reduce cardiac events particularly in high-risk patients. V4R can be used as to locate the site of obstruction.

Materials and methods: 81 patients with acute inferior myocardial infarction admitted to the coronary care unit (CCU) within 12 hours after the onset of chest pain who underwent coronary angiogram were included in the study. Standard 12-lead ECG with right precordial lead V4R was recorded. Patients were categorized into within 3 groups according to early changes of V4R-Group$I$ - ST-segment elevation $\geq 1 \mathrm{~mm}$ and positive T-wave, Group-II-ST-segment iso-electric and positive T-wave, Group-III-ST-segment depression $>1 \mathrm{~mm}$ and negative $T$-wave.

Results: In group I patients, highest percentage of the patients had lesion in proximal RCA (97.2\%); whereas in group II patients, highest percentage in the distal RCA (89.7\%) followed by LCX (41.4\%) and in group III patients, highest percentage also in LCX (100.0\%) followed by LAD (56.3\%). Based on analysis of sensitivity and specificity, it was revealed that in group I patients of ECG finding suggested $100.0 \%$ sensitivity, $97.8 \%$ specificity and $98.8 \%$ accuracy. In group II patients, 92.9\% sensitivity, $94.3 \%$ specificity and $93.8 \%$ had accuracy. In case of group III patients, $93.8 \%$ sensitivity, 98.5\% specificity and $97.5 \%$ accuracy.

Conclusion: The configuration of the ST-T segment in lead V4R is a sensitive and specific tool to recognize the occluded vessel in acute inferior MI whether it is proximal RCA, distal RCA or LCX. Since it is an inexpensive method, it can be readily used to locate the site of occlusion in AMI Inferior.
\end{abstract}

(Cardiovasc. j. 2011; 4(1): 46-52)

\section{Introduction:}

Coronary heart disease (CHD) is the most common cardiovascular disease and the major cause of death in middle-aged and older people. Despite steady progress in the management of cardiovascular diseases, people are still dying of these diseases and substantial early mortality remains.

AMI is a major component of acute coronary syndrome which usually due to anterior and or inferior wall involvement. The presentation of acute myocardial infarction is different depending on the coronary artery involved. Inferior wall MI results from either right coronary artery (RCA) or left circumflex coronary artery (LCX) occlusion. RCA predominantly supply the part of conducting system, right atrium, right ventricle part of left ventricle and the posteromedial papillary muscle. Occlusion of it may cause RV infarction with hypotension, cardiogenic shock, and different types of conduction disturbance, mitral regurgitation and sudden death. The LCX perfuses the posterior wall and variably the inferior and lateral segments. Lesion of it causes arrhythmias, heart failure and sudden death.

The occurrence of an inferior left ventricular infarction involving the right ventricle ranges from $14 \%$ to $84 \%$, but is typically thought to be about $50 \% .^{1}$ The incidence of right ventricular infarction in acute inferior MI settings is about $30 \% .^{2}$ In most cases RVI is caused by a proximal occlusion of right coronary artery. ${ }^{3}$

Address of Correspondence: Dr Saidul Alam, Consultant Cardiologist, National Institute of Ophthalmology, Dhaka, Bangladesh. 
The mortality of patient with only inferior wall acute inferior myocardial infarction (AMI) is $5-6 \%$, which increases to $25-30 \%$ along with the involvement of right ventricle. The patients with RVI had a higher in-hospital mortality rate (31 percent vs. 6 percent, $\mathrm{P}<0.001$ ) and a higher incidence of major in-hospital complications (64 percent vs. 28 percent, $\mathrm{P}<0.001$ ) than did those without RVI.

So, the patient with inferior wall AMI, site of culprit lesions is an important determinant of outcome. ${ }^{4}$ Patient with RV infarction have a poor prognosis whereas those with occlusion of LCX have a good prognosis.

Early diagnosis and treatment substantially reduce cardiac events particularly in high-risk patients. More precise localization of site of occlusion (proximal RCA, distal RCA or LCX) is important for prognostic and management purpose.

In RCA \& LCX occlusion, different configuration of ST-T segment changes occurred in leads - II, III, I, aVL, aVR, V1-V6. But by single right sided precordial lead V4R, we can easily and preciously predict the culprit coronary artery lesions in different sites of RCA \& LCX.

In the mid-1970s, Erhardt et al.- showed that a true right ventricular lead V4R was of value in the diagnosis of right ventricular infarction in patients with acute inferior myocardial infarction. ${ }^{5}$ The diagnosis was made when ST-segment elevation was present in lead V4R. In fact, lead V4R emerged as a reliable marker of the site of coronary-artery occlusion in acute inferoposterior myocardial infarction, either proximal or distal to the right ventricular branch of the right coronary artery or the circumflex coronary artery. Occlusion of the proximal right coronary artery obviously leads to right ventricular involvement. ${ }^{6}$

The ECG is rapid non-invasive affordable, easy and essentially without any non- adverse effects. Considering these much effort has put into correlation ECG changes in acute inferior wall MI with coronary angiogram. In this regard there was no study in our country. But it was very much feasible in our settings. So the objectives of this study were to analyze the changes in V4R to determine the site of coronary artery lesions in acute inferior myocardial infarction.

\section{Methodology}

Hypothesis of the study was ST- T changes in V4R predict the site of coronary artery lesion in acute inferior myocardial infarction. General objective was to correlate early ST-T changes in V4R with angiographic site of lesion in acute inferior myocardial infarction. Specific objective was a) to evaluate early changes in V4R in acute inferior myocardial infarction. b) Early detection of highrisk patient in acute inferior myocardial infarction.

It was an observational study conducted in Department of cardiology, NICVD, Dhaka from October 2006 to May 2007. Patients with acute inferior myocardial infarction admitted to the coronary care unit (CCU) within 12 hours after the onset of chest pain who underwent coronary angiogram were included in the study. Patients with previous anterior and or inferior myocardial infarction, reinfarction before catheterization, associated acute anterior myocardial infarction, and bundle branch block, pericardial diseases, patient dependant on pacemaker and cardiomyopathy were excluded from the study.

Initially 100 patients were followed up during hospital period, 12 patients refused for angiogram, 88 patients underwent CAG. We could not properly identify the culprit coronary artery lesion from CAG in 7 patients and were excluded. So a total 81 patients were considered for the present study. Baseline clinical data including demographic profile, clinical history and risk factors were recorded in a proforma on admission. Physical examination was done. Investigations including ECG, Echocardiography, blood sugar and renal function were recorded. After initial diagnosis, conventional treatment for acute inferior myocardial infarction was given. Standard 12-lead ECG with right precordial lead V4R was recorded within $12 \mathrm{hrs}$ after the onset of chest pain. Patients were categorized into 3 groups according to early changes of V4R- Group-I - ST-segment elevation $\geq 1 \mathrm{~mm}$ and positive T- wave, Group-II- ST-segment iso-electric and positive T-wave, Group-III- STsegment depression $\geq 1 \mathrm{~mm}$ and negative $\mathrm{T}$ - wave.

Within 7 to 10 days of hospital admission, the enrolled patients underwent CAG and coronary artery lesions were correlated with ECG findings. CAG was analyzed by visual estimation. $70 \%$ or more luminal stenosis was considered significant. 
Culprit lesion means artery that was considered as cause of MI. If both the right coronary and the left circumflex coronary arteries were diseased, the artery with the subtotal luminal narrowing or total obstruction was believed to be the cause of MI, and only arteries with a stenosis $75 \%$ were judged the cause of MI.

\section{Statistical analysis:}

Comparison between groups was done by student ' $t$ ' test, chi-square test as applicable. Probability less than $0.005(p<0.05)$ were considered as significant. To predict the culprit coronary artery lesion in proximal RCA, distal RCA or LCX by admission ECG: Comparison between the 12-lead ECG findings and coronary angiographic findings was done by statistical tests of accuracy. (Sensitivity, specificity, predictive value) using the $2 \times 2$ table method of validity test (after Dawson. 2004).

\section{Results:}

A total 81 patients were considered in this study. The main objective of the study was to correlate the ECG findings with the findings from the coronary angiography. Among the studied patients, 67 patients were male $(82.7 \%)$ and 14 patients were female (17.3\%) with male and female ratio was $4.78: 1$. The mean age of the patients was $53.6 \pm 10.3$ years ranging from 31 to 73 years. On an average 6.8 hours required attending the hospital after onset of chest pain ranging from 3.0 to 11.5 hours. It was found that about half of the patients (49.4\%) attended the hospitals within 5-7 hours of complaints followed by $24.7 \%$ within 8-9 hours and $14.8 \%$ within 5 hours. However, $11.1 \%$ of the patients attended after 10 hours of complaints.

\section{Table-I}

Distribution of the patients by duration of chest pain

\begin{tabular}{lcc}
\hline $\begin{array}{l}\text { Duration of chest } \\
\text { pain (hours) }\end{array}$ & $\begin{array}{c}\text { Frequency } \\
(\mathrm{n}=81)\end{array}$ & Percent \\
\hline$<5$ & 12 & 14.8 \\
$5-7$ & 40 & 49.4 \\
$8-9$ & 20 & 24.7 \\
$\geq 10$ & 9 & 11.1 \\
\hline
\end{tabular}

Among the studied patients, highest percentage of the patients had complaints of chest pain (95.1\%) followed by sweating (63.0\%), nausea (50.6\%), vomiting (32.1\%), and shortness of breathe (23.5\%).

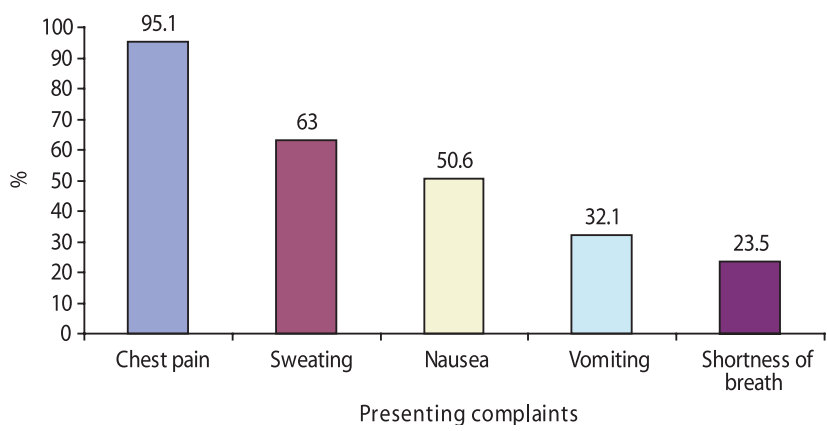

Fig.-1: Distribution of the patients by presenting complaints $(n=81)$

Considering the risk factors, smoking was most prevalent. More than half of the patients had history of smoking (56.8\%) followed by hypertension (46.9\%), diabetes mellitus (35.8\%), family history of CAD $(18.5 \%)$ and dyslipidaemia (14.8\%).

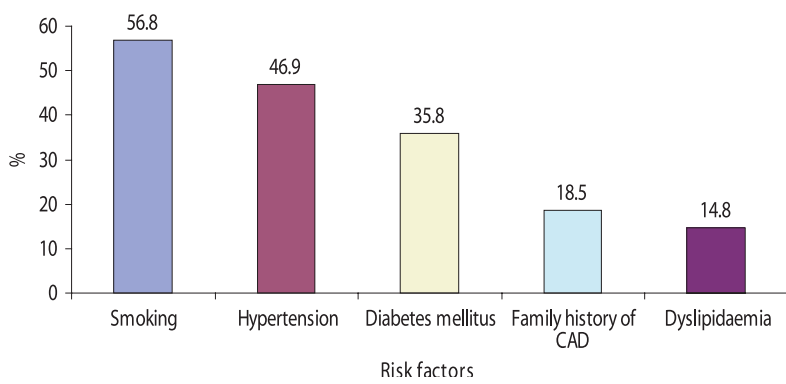

Fig.-2: Distribution of the patients by risk factors $(n=81)$

On admission, within 12 hours after the of onset chest pain standard 12 lead ECG with right sided precordial lead V4R was recorded.

Table-II

On admission initial ECG findings in Lead v4R $(n=81)$

\begin{tabular}{|c|c|c|}
\hline ECG findings & requency $(\mathrm{n}=81)$ & Percent \\
\hline $\mathrm{ST}$ elevation with $\mathrm{T} \mathrm{u}$ & 36 & 44.4 \\
\hline $\mathrm{ST}$ iso-electric with $\mathrm{T}$ upright & 29 & 35.8 \\
\hline $\mathrm{ST}$ depression with $\mathrm{T}$ inversior & 16 & 19.8 \\
\hline
\end{tabular}

Group I: ST elevation with T upright

Group II: ST iso-electric with T upright

Group III: ST depression with T inversion

Among the studied patients, $13.6 \%$ of them did not have any complications during hospital stay. The most frequent complications was hypotension (32.1\%) followed by second degree heart block (25.9\%), complete heart block (17.3\%), PVC (16.0\%), frist second degree heart block (6.2\%) asystole $(6.2 \%)$, cardiogenic shock $(6.2 \%)$, ventricular tachycardia (6.2\%), left ventricular failure (4.9\%) etc. 
Prediction of the Site of Coronary Artery Lesion in Acute Inferior Myocardial Infarction

Table-III

Distribution of study patients by Haemodynamics parameters in groups $(n=81)$

\begin{tabular}{|c|c|c|c|c|c|c|}
\hline \multirow[t]{2}{*}{ Haemodynamics } & \multicolumn{3}{|c|}{ Mean $\pm \mathrm{SD}$ (Range) } & \multicolumn{3}{|c|}{ pvalue } \\
\hline & $\begin{array}{c}\text { Group I } \\
(\mathrm{n}=36)\end{array}$ & $\begin{array}{c}\text { Group II } \\
(\mathrm{n}=29)\end{array}$ & $\begin{array}{c}\text { Group III } \\
(\mathrm{n}=16)\end{array}$ & $\begin{array}{c}\text { Group I } \\
\text { Vs II }\end{array}$ & $\begin{array}{c}\text { Group I } \\
\text { Vs III }\end{array}$ & $\begin{array}{c}\text { Group II } \\
\text { Vs III }\end{array}$ \\
\hline Pulse rate /minute & $\begin{array}{c}60.2 \pm 19.2 \\
(30-96)\end{array}$ & $\begin{array}{c}75.7 \pm 14.7 \\
(32-96)\end{array}$ & $\begin{array}{c}85.8 \pm 7.3 \\
(68-96)\end{array}$ & $0.590^{\mathrm{NS}}$ & $0.001^{\mathrm{S}}$ & $0.001^{\mathrm{S}}$ \\
\hline $\begin{array}{l}\text { Systolic blood } \\
\text { pressure (mmHg) }\end{array}$ & $\begin{array}{c}100.6 \pm 23.7 \\
(55-170)\end{array}$ & $\begin{array}{c}116.6 \pm 10.7 \\
(100-140)\end{array}$ & $\begin{array}{c}110.6 \pm 7.5 \\
(95-125)\end{array}$ & $0.007^{\mathrm{S}}$ & $0.404^{\mathrm{NS}}$ & $0.014^{\mathrm{S}}$ \\
\hline $\begin{array}{l}\text { Diastolic blood } \\
\text { pressure (mmHg) }\end{array}$ & $\begin{array}{c}64.2 \pm 15.2 \\
(40-95)\end{array}$ & $\begin{array}{c}77.1 \pm 11.6 \\
(55-95)\end{array}$ & $\begin{array}{l}70.6 \pm 7.7 \\
(55-85)^{\mathrm{S}}\end{array}$ & $0.001^{\mathrm{S}}$ & $0.451^{\mathrm{NS}}$ & 0.016 \\
\hline
\end{tabular}

Table-IV

Distribution of the patients by in-hospital complications and grouping of the patients $(n=81)$

\begin{tabular}{|c|c|c|c|c|c|c|}
\hline \multirow{3}{*}{$\begin{array}{l}\text { In-hospital } \\
\text { complications }\end{array}$} & \multicolumn{6}{|c|}{ Study patients } \\
\hline & \multicolumn{2}{|c|}{ Group I $(n=36)$} & \multicolumn{2}{|c|}{ Group II $(n=29)$} & \multicolumn{2}{|c|}{ Group III $(n=16)$} \\
\hline & No. & $\%$ & No. & $\%$ & No. & $\%$ \\
\hline Hypotension & 24 & 66.7 & 2 & 12.5 & 0 & 0.0 \\
\hline Cardiogenic shock & 1 & 2.8 & 1 & 6.3 & 3 & 18.8 \\
\hline LVF & 0 & 0.0 & 1 & 6.3 & 3 & 18.8 \\
\hline First degree heart block & 5 & 13.9 & 0 & 0.0 & 0 & 0.0 \\
\hline Second degree heart block & 15 & 41.7 & 4 & 25.0 & 2 & 12.5 \\
\hline Complete heart block & 13 & 36.1 & 1 & 6.3 & 0 & 0.0 \\
\hline $\mathrm{RBBB}$ & 0 & 0.0 & 2 & 12.5 & 1 & 6.3 \\
\hline $\mathrm{LBBB}$ & 0 & 0.0 & 1 & 6.3 & 1 & 6.3 \\
\hline Asystole & 5 & 13.9 & 0 & 0.0 & 0 & 0.0 \\
\hline Atrial fibrillation & 1 & 2.8 & 1 & 6.3 & 1 & 6.3 \\
\hline Ventricular fibrillation & 2 & 5.6 & 0 & 0.0 & 1 & 6.3 \\
\hline Ventricular tachycardia & 3 & 8.3 & 0 & 0.0 & 2 & 12.5 \\
\hline PVC & 2 & 5.6 & 11 & 68.8 & 0 & 0.0 \\
\hline No complication & 5 & 13.9 & 3 & 18.8 & 3 & 18.8 \\
\hline
\end{tabular}

Table-V

Comparative distribution of the patients by site of lesion and grouping of patients $(n=81)$

\begin{tabular}{|c|c|c|c|c|c|c|}
\hline \multirow[t]{3}{*}{ Site of lesion } & \multicolumn{6}{|c|}{ Study patients } \\
\hline & \multicolumn{2}{|c|}{ Group I $(\mathrm{n}=36)$} & \multicolumn{2}{|c|}{ Group II $(n=29)$} & \multicolumn{2}{|c|}{ Group III ( $\mathrm{n}=16)$} \\
\hline & No. & $\%$ & No. & $\%$ & No. & $\%$ \\
\hline Proximal RCA & 35 & 97.2 & 3 & 10.3 & 5 & 31.3 \\
\hline Distal RCA & 10 & 27.8 & 26 & 89.7 & 3 & 18.8 \\
\hline LCX & 8 & 22.2 & 12 & 41.4 & 16 & 100.0 \\
\hline $\mathrm{LAD}$ & 19 & 52.8 & 17 & 58.6 & 9 & 56.3 \\
\hline
\end{tabular}


In group I patients, highest percentage of the patients had lesion in proximal RCA (97.2\%); whereas in group II patients, highest percentage in the distal RCA (89.7\%) followed by LCX (41.4\%) and in group III patients, highest percentage also in LCX (100.0\%) followed by LAD (56.3\%).

Table-VI

Sensitivity and specificity analysis of $C A G$ findings and $E C G$ findings $(n=81)$

\begin{tabular}{lccc}
\hline \multirow{2}{*}{ Study patients } & \multicolumn{3}{c}{ Percentage } \\
\cline { 2 - 4 } & Sensitivity & Specificity & Accuracy \\
\hline Group I & 100.0 & 97.8 & 98.8 \\
Group II & 92.9 & 94.3 & 93.8 \\
Group III & 93.8 & 98.5 & 97.5 \\
\hline
\end{tabular}

Based on analysis of sensitivity and specificity, it was revealed that in group I patients of ECG finding suggested $100.0 \%$ sensitivity, $97.8 \%$ specificity and $98.8 \%$ accuracy. In group II patients, $92.9 \%$ sensitivity, $94.3 \%$ specificity and $93.8 \%$ had accuracy. In case of group III patients, 93.8\% sensitivity, $98.5 \%$ specificity and $97.5 \%$ accuracy.

\section{Discussion:}

The major determinants of the immediate and longterm outcome of acute myocardial infarction are the site and size of infarct and the functional status of the residual myocardium. About 50 percent deaths associated with acute MI occur within an hour of the events and are attributable, most often from ventricular fibrillation. The ECG remains a crucial tool in the identification and management of acute MI. The analysis of patterns of ST-T segment in right precordial lead V4R may influence decisions regarding the treatment strategy. The early and accurate identification of the infarct related artery on the ECG could help to predict the amount of myocardium at risk and guide decisions regarding the urgency of revascularization.

This study was conducted to find out the role of initial different configuration of ST- T segment changes in right precordial lead V4R, to predict the site of culprit coronary artery lesion in patients with inferior MI.
Among the studied patients, 67 were male (82.7\%) and 14 were female (17.3\%), with male and female ratio was $4.78 \pm 1$. The result was consistent with the result of other studies where the percentage of male patient was 89,90 and 92 respectively. ${ }^{2}$ However, no statistically significant mean sex difference was founds between patients of study group ( $\mathrm{p}>0.05)$.

The mean age of the patients was $53.6 \pm 10.3$ years. The mean age of male patients was $52.9 \pm 10.8$ years and that of female patients was $57.0 \pm 6.9$. The highest number of patients was in the age group 55 to 64 years. However no statistically significant mean age difference was found between male and female in different groups of patients $(p>0.05)$. These findings are consistent with other studies conducted in our institute. ${ }^{7,8}$

The important risk factors in studied patients were history of smoking (56.8\%) followed by hypertension (46.9\%), diabetes mellitus (33.2\%), dyslipidaemia (12.5\%) and family history of early onset CAD (18\%). The composite risk factors in terms of smoking, hypertension, diabetes mellitus, family history of CAD and dyslipidaemia were $96 \%$ and $4 \%$ had no risk factor. This data are almost similar to the study done in Bangladesh. ${ }^{8}$ In that study the highest percentage of patients had history of smoking (49.1\%) followed by hypertension (43.6\%), diabetes mellitus (36.4\%), dyslipidaemia (16.4\%) and family history of CAD (12.7\%). Studies done by Jamaluddin et al. ${ }^{7}$ and Khaleque $^{8}$ also reported similar data.

Among the studied patients, the most frequent complications were hypotension (32.1\%) followed by second degree heart block (25.9\%), complete heart block (17.3\%), premature ventricular contraction (16.0\%), first degree heart block (6.2\%), asystole $(6.2 \%)$, cardiogenic shock $(6.2 \%)$, ventricular tachycardia (6.2\%), ventricular fibrillation(3.7\%) and left ventricular failure (4.9\%). $13.6 \%$ patients had no complications during hospital stay. Among the hypotension group, 22 patients had raised jugular venous pressure and the clear lungs. Hypotension, first degree heart block second degree heart block, complete heart block, asystole, were more common in group I patients. Cardiogenic shock and acute LVF were common in-group III patients. 
In 43 patients of acute inferior MI, Majumder $\mathrm{AAS}^{9}$ showed that overall conduction disturbance were $58.14 \%$. Of them $53.48 \%$ were atrioventricular and $4.65 \%$ were intraventricular conduction disturbance. The study done by Shawkat et al. ${ }^{10}$ stated that conduction disturbance in acute inferior MI patients were $49.3 \%$ and it was more common in RVI (28.7\%) than inferior MI without RVI (17.6\%). Dysrhythmias such as bradycardia, highdegree atrioventricular block, and atrial fibrillation are associated with approximately $50.0 \%$ patients of inferior MI and complete heart block is common in RVI. ${ }^{11}$ These results coincide with the present study. In another study of 50 patients with acute inferior myocardial infarction with right ventricular involvement, $26 \%$ had raised JVP, $36 \%$ had hypotension, which is also consistent with the present study. ${ }^{12}$

On admission ECG finding in lead V4R, among the study 81 patients: Group I (ST elevation with T upright) had 36(44.4\%) patients, Group II (ST isoelectric with $\mathrm{T}$ upright) had 29(35.8\%) patients and Group III (ST depression with T inversion) had 16(19.8\%) patients. A study done by Khan S et al. (2004) showed, among 100 inferior MI patients $54(54 \%)$ had ST elevtion $>1 \mathrm{~mm}$ in V4R and 46(46\%) had no ST elevation in V4R. In 522 study patients with inferior MI, ST elevation in lead V4R $>1 \mathrm{~mm}$ was $169(32 \%)$, rest was non-ST elevation $253(68 \%) .{ }^{13}$ In a study of 84 patients with inferior MI, Braat SH et al. ${ }^{14}$ showed 34(40.47\%) had ST elevation with T upright, $29(34.52 \%)$ had ST isoelectric with $\mathrm{T}$ upright and 21(25.0\%) had ST depression with $\mathrm{T}$ inversion, which are consistent with the present study.

According to CAG findings: Out of 36 patients in group I, 35 had culprit lesion in proximal RCA and 1 had in distal RCA. So, the sensitivity specificity to diagnose the lesion in the proximal RCA from V4R analysis of ECG was 100.0\%, 97.8\%, and 98.8\%. The presence of ST- segment elevation e" $1 \mathrm{~mm}$ in lead V4R has a sensitivity of $100 \%$ and a specificity of $87 \%$ for occlusion of the RCA above the RV branch; the predictive accuracy is $92 \% .{ }^{13}$ Out of 29 patients in-group II, 26 had culprit lesion in distal RCA, 2 had in proximal RCA and 1 had in LCX. So, the sensitivity specificity to diagnose the lesion in the distal RCA from V4R analysis of ECG was $92.9 \%, 94.3 \%$, and $93.8 \%$. Out of 16 patients in-group III, 15 had culprit lesion in LCX and 1 had in distal RCA. So, the sensitivity specificity to diagnose the lesion in the LCX from V4R analysis of ECG was $93.8 \%, 98.5 \%, 97.5 \%$. Among the studied 81 patients, $7(45.7 \%)$ had culprit lesion in proximal RCA, 28(34.6\%) had in distal RCA and rest 16(19.8\%) in LCX. Most of the lesion of study group was situated in right coronary artery proximal to RV branch. Ahmed $\mathrm{F}^{15}$ showed among 56 patients of inferior MI, 44(78.57\%) had in RCA lesion and $12(21.43 \%)$. Terry et al. ${ }^{16}$ showed in 50 patients of inferior MI, 35(70\%) had lesion in proximal RCA, 10(20\%) had in distal RCA and 5(10\%) had in LCX.

In 84 patients with an acute inferior MI; 27 had stenosis proximal to the RV branch, 36 had stenosis distal to the RV branch of right coronary artery and 21 had stenosis in the LCX. The presence of ST- segment elevation e" $1 \mathrm{~mm}$ in lead V4R has a sensitivity of $100 \%$ and a specificity of $87 \%$ for occlusion of the RCA above the RV branch; the predictive accuracy is $92 \% .{ }^{14}$ In another study among 107 patients with an acute inferior MI; the sensitivity, specificity and diagnostic accuracy to predict the site of culprit coronary artery lesion in proximal RCA, distal RCA and LCX were- $93.0 \%$, $88.7 \%, 85.5 \%$ \& $76.7 \%, 92.1 \%, 73.4 \%$ \& $85.4 \%$, $97.7 \%, 93.0 \%$ respectively. ${ }^{17}$ The ST segment elevation of ${ }^{3} 1 \mathrm{~mm}$ in lead V4R was found to have the greatest sensitivity-93\% and predictive accuracy- $93 \%$ by Boersma et al. ${ }^{16}$ These results are similar with the present study.

\section{Conclusion:}

So, it may be concluded that the configuration of the ST-T segment in lead V4R is a sensitive and specific tool to recognize the occluded vessel in acute inferior MI whether it is proximal RCA, distal RCA or LCX. Since it is an inexpensive method, it can be readily used in every hospital. Recording of right-sided precordial lead, particularly V4R should be done in all patient admitted with acute inferior myocardial infarction.

\section{References:}

1. Chockalingam A, Gnanavelu G, Subramaniam T, Dorairajan S, Chockalingam V . Right ventricular myocardial infarction. Angiology 2005;56:371-376.

2. Majumder AAS, Haque A, Haque M, Haque SA, Chowdhury,S. Right ventricular involvement in acute myocardial infarction: course, complications and 
management- an experience at a teaching Hospital. Journal of Institute of Postgraduate Medicine \& Research 1996; 11: 22-25.

3. Terry R, Bowers W, William W, Neil O, Pica M, James A, Goldstein M. Patterns of coronary compromise resulting in acute right ventricular ischemic dysfunction. Circulation 2002; 114:106-110.

4. Zehender M, Kasper W, Kauder E, Schonthaler M, Geibel A, Olschewski M, Just, H. Right ventricular infarction as an independent predictor of prognosis after acute inferior myocardial infarction. New England journal of Medicine 1993; 328: 981-988.

5. Erhardt HO, Todriman T, Ninio R, Sjogren A, Wahlberg I. The single right sided precordial lead in the diagnosis of Right ventricular involvement in inferior myocardial infarction. American Heart Journal 1976; 91: 571-578.

6. Braat SH, Brugada P, Zwaan C, Barbash GI, Allen J, Dull K, Ommen V, Coenegracht JM, Wellens HJ. Value of ECG in diagnosing right ventricular involvement with acute inferior wall myocardial infarction. British Heart Journal 1983; 49: 368-372.

7. Jamaluddin M, Haque KMHSS, Chowdhury AHK, Zaman MA. Short Term (1 month) Prognosis of Patients of Acute Myocardial Infarction Receiving Thrombolytic Therapy. Bangladesh Heart J 1997; 12(2): 54-58.

8. Khaleque A. Coronary angiographic co-relation of TIMI risk scoring in acute ST-elevated myocardial infarction and 30 days outcome. (Thesis MD Cardiology). Dhaka: National Institute of Cardiovascular Diseases (NICVD). 2004.

9. Majumder AAS. Conduction disturbances in acute myocardial infarction (Thesis, MD Cardiology). Dhaka: National Institute of Cardiovascular diseases.1991.
10. Shawkat AH, Assad M. Right ventricular infarctionDiagnosis and Treatment. Clinical Cardiology 2000; 23: $473-482$.

11. Mittal SR. Isolated Right ventricular infarction. International Journal of Cardiology 1994; 46: 53-60.

12. Chockalingam A, Gnanavelu G, Subramaniam T, Dorairajan S, Chockalingam V. Right ventricular myocardial infarction. Angiology 2005; 56: 371-376.

13. Zeymer UWE, Neuhaus KL, Tebbe U, Molhoek P, Schroder R. Effects of thrombolytic therapy in acute inferior myocardial infarction with or without right ventricular involvement. J Am Coll Cardiol 1998; 32 : 876-81.

14. Braat SH, Karel Pedro, Brugada, Dulk, Vincent, Ommen, Hein, Vincent, Weallens JJ. Value of Lead $\mathrm{V} 4 \mathrm{R}$ for Recognition of the Infarct Coronary Artery in Acute Inferior Myocardial Infarction. Am J Cardiol 1984; 53: $1538-1541$.

15. Ahmed F. Prediction of either Right Coronary Artery or Left Circumflex Artery occlusion in Inferior wall Acute Myocardial Infarction by electrocardiographic criteria (Thesis, MD Cardiology). Dhaka : National Institute of Cardiovascular Diseases(NICVD). 2003.

16. Terry R, Bowers W, William W, Neil O, Pica M, James A, Goldstein M. Patterns of coronary compromise resulting in acute right ventricular ischemic dysfunction. Circulation 2002; 114: 106-110.

17. Anton PM, Gorgels, Braat SH, Gorgels, Frits W, Bar, Hein AW. Value of ST - segment in lead V4R in inferior wall myocardial infarction to predict the site of coronary arterial occlusion. The American Journal of Cardology 1988; 62:140-142.

18. Boersma E, Mircade N. ECG evaluation in all acute myocardial infarction. Lancet 2003; 361:847-858. 